reliable information on the nature of the middle-ear process. As a simple and immediately pain-relieving measure it is therefore highly recommended and should always be performed when treating a child with acute symptoms and fluid in the middle ear.

Finally, nasal or oral decongestants of any type have not been established to have any beneficial effect in the prevention or treatment of either acute or secretory otitis media. ${ }^{7}$ Since, besides their well-known side effects, oral decongestants may even be harmful to the middle ear, ${ }^{7}$ they should not be routinely used for otitis media.

Pekka Karma

Department of Clinical Sciences.

University of Tampere,

Tampere 52, Finland

Klcin JO. Ann ()tol Rhinol Laryngol $1981 ; 90$ suppl 84 : 30-36.

Luotonen J, Herva E, Karma P, Timonen $M$, L einonen $M$, Mäkelä $\mathrm{PH}$. Scand f Infect Dis (in press).

crberts (i, Jeppsson P-H, Nylén (), BraneforsHelander P Pract Ororhinolurvngol i971;33:191202.

Kamme (') Lundgren K,

Ginsburg CM Micracken GH, Jr, Nelson J1). Ann ()tol Rhinol Larvngol $1981 ; 90$ suppl 84:37-43.

Karma P. Br Mid f 1976;i:1018.

Sorri M, Sipilä P, P'alva A, Karma P. Acta Otolaryngol, in press.

\section{Management of patients with} bilateral amputations

SIR,-I refer to your leading article (12 September, p 684) regarding the management of double amputees. This contains several very valid points, in particular that the home environment is often woefully unsuitable for the returning double amputee-regardless of how well he may have performed on his new prostheses in the walking-training school. The level of communication between all those concerned in amputee rehabilitation could certainly be improved with advantage. I also agree that the greater use of purely cosmetic limbs for double amputees permanently confined to wheelchairs should be encouraged. There are, however, several misconceptions which need to be corrected.

Reference is made to "halting the automatic prescription of a sequence of prostheses." In fact, the need or otherwise for an artificial limb would have been considered much earlier by the multidisciplinary care team. It is implied that the artificial limb and appliance centres issue, almost inexorably, a series of limbs to every amputee. This is not the case. All patients referred to our service are first medically assessed. Not infrequently it is decided, after consideration of all relevant factors, that a wheelchair existence would be in the patient's own best interest. In marginal cases a trial of pylons may be undertaken, while in more straightforward cases the amputee will advance-subject to satisfactory progress at every stage-from short- to longrocker pylons and finally to a pair of definitive limbs. There is no automatic prescription.

You demonstrate a rather negative approach to what may have to be done as a lifesaving measure. The more positive attitude might have been to stress the advantages of the belowknee procedure over any higher level operation, where this is clinically possible. In this way the speed and end-result of rehabilitation would be greatly improved. It is particularly important to remember that where amputation has been performed in a single amputee for arteriosclerosis, approximately $30^{\prime \prime} "$ will be double amputees within three years. Even the retention of one knee joint can strikingly enhance future mobility.

The third paragraph states that those with double amputations above the knee are expected to walk and are given artificial limbs irrespective of their physical and mental ability to cope with them. As pointed out this is not the case. Each amputee receives a complete assessment from the artificial limb and appliance centre medical officer, and the patient's mental approach is taken into account in any decision to proceed.

You state correctly that the initial assessment is made by the hospital team but this should occur before operation and not "as soon as postoperative recovery permits." The artificial limb and appliance centre medical officer and the prosthetist (limb fitter) should be part of the multidisciplinary team, as they are at Roehampton.

A double amputee cannot be tested, as you suggest, to see whether he is suited to walking with prostheses before being referred to the artificial limb and appliance centre. Pneumatic pylons are not suitable for double-above-knee amputees since they rub together and are unstable, nor is it recommended that a pneumatic pylon should be paired with the patient's original prosthesis supplied when a single amputee. The latter requires shortening, and this must be done at the artificial limb and appliance centre.

Learning to walk again as a double amputee is an entirely new experience, which is why the majority are started on a very short $(24 \mathrm{in}, 61$ $\mathrm{cm}$ ) pair of rocker pylons; for reasons of stability such a patient is seldom restored to his original height. The result of any assessment of a recent double amputee using his original and unaltered prosthesis would be quite false and in fact could lead to unfair rejection.

Also the apparent cost of two pairs of artificial limbs is quoted. This does not represent the cost of hardware alone but includes a significant element covering the bespoke fitting service provided throughout the country.

Finally, in the last paragraph it seems a little rash to assume that administrative procedures in the NHS are necessarily more efficient than in the DHSS or that postal delays would be any less following transfer.

Limb Fitting Centre,

A W G ENGLISH

\section{Gamma-aminobutyric acid and weight control}

SIR,-Two papers in two recent editions may be brought together. Drs J Egger and E M Brett (29 August, p 577) report that weight gain is found with the antiepileptic drug sodium valproate and that weight loss was also seen on withdrawal. Dr $\mathrm{H}$ Petursson and Professor M H Lader (5 September, p 643) describe noticeable weight loss on withdrawal of benzodiazepine treatment. Both drugs are thought to increase brain $\gamma$-aminobutyric acid. ${ }^{1} 3$ The formation enzyme of $\gamma$-aminobutyric acid, glutamic acid decarboxlyase, is decreased by approximately half in the brains of patients dying of protracted illnesses in contrast to those who die suddenly, ${ }^{4}$ and in contrast to choline acetyl transferase and catecholamines. ${ }^{5}$ :

These separate experimental findings suggest that $\gamma$-aminobutyric acid has some influence on weight control, and an application would be a trial of benzodiazepines in cachexic conditions and during the almost inevitable nitrogen loss postoperatively. The conventional treatment of anorexia nervosa with chlopromazine could also be reviewed.

M WELLER

Royal Free Hospital,

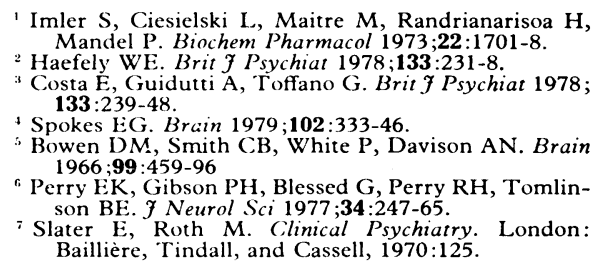

Stridor

SIR,-I read Dr H B Valman's article on stridor (25 July, p 294) and the letters it provoked from Drs M G Addy and N R Bennett (12 September, p 729) with interest.

A review of 36 patients with stridor admitted to hospitals in Oxford in 1979 showed that most (26) were due to laryngotracheobronchitis and required no active management. Of the five children who required an artificial airway (nasotracheal intubation), however, three had laryngotracheobronchitis and two had epiglottitis. The clinical picture in these five cases was the same.

These figures suggest to me that the two types of croup are not all that different. Stridor thought to be due to a viral infection (laryngotracheobronchitis) should be taken every bit as seriously as that thought to be due to a bacterial infection (epiglottitis). Clinically the two conditions are often indistinguishable. Possibly one child in ten admitted to hospital with laryngotracheobronchitis will require an artificial airway.

It is wrong to say that nasotracheal intubation guarantees safety. Twice I have seen nasotracheal tubes block with disastrous or near disastrous consequences. Nursing a child with a nasotracheal tube in place requires the highest standards and individual attention. I would suggest these children should not be nursed on a busy ward but in the intensive care unit. In Oxford a clear protocol has been laid down for dealing with a child with stridor. It involves the senior registrars in anaesthetics and ENT as well as the paediatricians on call. A picture of a child with epiglottitis is being prepared which will be displayed on the walls of the casualty department and in the wards to remind new staff of the clinical picture of a child with acute epiglottitis or croup.

Piers Rowlandson

John Radcliffe Hospital,

John Radcliffe Hosp
Oxford OX3 9DU

\section{Points}

\section{Management of asthma in the child aged under 6 years}

Dr JANna Frears (Children's Asthma Clinic, Beaumont House Chest Clinic, Plymouth PL4 9BQ) and Mr A G Butler (Glaxo Group Research Ltd, Herts SG12 0DJ) write: Dr C J Bacon (11 July, p 141) has pointed out the possible benefits of nebulised corticosteroid treatment in the severely affected young child 